\title{
Identification of IncRNA and mRNA expression profiles in rat spinal cords at various time-points following cardiac ischemia/reperfusion
}

\author{
QIAN WANG $^{1 *}$, ZHI-XIAO LI ${ }^{1 *}$, YU-JUAN LI ${ }^{1}$, ZHI-GANG HE $^{2}$, YING-LE CHEN $^{3}$, \\ MAO-HUI FENG ${ }^{4}$, SHUN-YUAN LI ${ }^{3}$, DUO-ZHI WU ${ }^{5}$ and HONG-BING XIANG ${ }^{1}$
}

\begin{abstract}
Departments of ${ }^{1}$ Anesthesiology and Pain Medicine and ${ }^{2}$ Emergency Medicine, Tongji Hospital, Tongji Medical College, Huazhong University of Science and Technology, Wuhan, Hubei 430030; ${ }^{3}$ Department of Anesthesiology,

The First Affiliated Quanzhou Hospital of Fujian Medical University, Quanzhou, Fujian 362000; ${ }^{4}$ Department of Oncology,

Wuhan Peritoneal Cancer Clinical Medical Research Center, Zhongnan Hospital of Wuhan University,

Hubei Key Laboratory of Tumor Biological Behaviors and Hubei Cancer Clinical Study Center, Wuhan, Hubei 430071;

${ }^{5}$ Department of Anesthesiology, People's Hospital of Hainan Province, Haikou, Hainan 570311, P.R. China
\end{abstract}

Received October 20, 2018; Accepted March 20, 2019

DOI: $10.3892 / \mathrm{ijmm} .2019 .4151$

\begin{abstract}
The identification of the expression patterns of long non-coding RNAs (lncRNAs) and mRNAs in the spinal cord under normal and cardiac ischemia/reperfusion (I/R) conditions is essential for understanding the genetic mechanisms underlying the pathogenesis of cardiac I/R injury. The present study used high-throughput RNA sequencing to investigate differential gene and lncRNA expression patterns in the spinal cords of rats during I/R-induced cardiac injury. Male Sprague Dawley rats were assigned to the following groups: i) Control; ii) $2 \mathrm{~h}$ ( $2 \mathrm{~h}$ post-reperfusion); and iii) $0.5 \mathrm{~h}$ ( $0.5 \mathrm{~h}$ post-reperfusion). Further mRNA/lncRNA microarray analysis revealed that the expression profiles of IncRNA and mRNA in the spinal cords differed markedly between the control and $2 \mathrm{~h}$ groups, and in total 7,980 differentially expressed ( $>2$-fold) IncRNAs (234 upregulated, 7,746 downregulated) and 3,428 mRNAs (767 upregulated, 2,661 downregulated) were identified. Reverse transcription-quantitative polymerase chain reaction analysis was performed to determine the expression patterns of several lncRNAs. The results indicated
\end{abstract}

Correspondence to: Professor Hong-Bing Xiang, Department of Anesthesiology and Pain Medicine, Tongji Hospital, Tongji Medical College, Huazhong University of Science and Technology, 1095 Jiefang Avenue, Wuhan, Hubei 430030, P.R. China E-mail: xhbtj2004@163.com

Dr Duo-Zhi Wu, Department of Anesthesiology, People's Hospital of Hainan Province, 19 Xiuhua Road, Haikou, Hainan 570311, P.R. China

E-mail: 13976674619@163.com

*Contributed equally

Key words: cardiac ischemia/reperfusion, spinal cord, long non-coding RNA, mRNA, rat, translational medicine that the expression levels of 1ncRNA NONRATT025386 were significantly upregulated in the 2 and $0.5 \mathrm{~h}$ groups when compared with those in the control group, whereas the expression levels of NONRATT016113, NONRATT018298 and NONRATT018300 were elevated in the $2 \mathrm{~h}$ group compared with those in the control group; however, there was no statistically significant difference between the $0.5 \mathrm{~h}$ and control groups. Furthermore, the expression of lncRNA NONRATT002188 was significantly downregulated in the 0.5 and $2 \mathrm{~h}$ groups when compared with the control group. The present study determined the expression pattern of lncRNAs and mRNAs in rat spinal cords during cardiac I/R. It was suggested that lncRNAs and mRNAs from spinal cords may be novel therapeutic targets for the treatment of I/R-induced cardiac injury.

\section{Introduction}

Cardiac ischemia/reperfusion (I/R) injury is associated with various etiological factors (1-3), including primary heart conditions, and neuropathic, vascular or systemic disorders. However, the pathological origin of I/R-induced cardiomyocyte death remains poorly understood. The neuropathic accumulation associated with myocardial I/R is thought to directly or indirectly activate sensory or sympathetic fibers that innervate the heart. However, as the underlying heart-specific neuronal pathway and mechanism are unknown, neurogenic therapeutic interventions often only have limited success.

It is well established that the autonomic nervous system serves a crucial physiological role in regulating cardiac function (4-9). Previous studies have demonstrated that some myocardial ischemic events are triggered by the autonomic nervous system, and a sympathetic-parasympathetic imbalance may lead to the pathophysiological development of myocardial ischemia $(10,11)$. Our previous study revealed that an injection of retrograde tracer pseudorabies virus (PRV)-614 into the left ventricle wall in mice resulted in the retrograde infection 
of neurons in the intermediolateral nucleus of the spinal cord and the rostral ventrolateral medulla of the brainstem via the sympathetic pathway (12). The spinal cord has been implicated in the pathogenesis of cardiac injury caused by I/R (4,13-16). Furthermore, there is convincing evidence that the heart receives dense innervation from sensory afferent fibers, which peripherally release a variety of vasodilator neuropeptides, such as calcitonin gene-related peptide (CGRP) (17) and substance $\mathrm{P}$ (SP), in response to local stimuli (18). Despite extensive research in this area, the mechanisms underlying cardiac I/R injury are largely unknown. Therefore, there is an urgent requirement for more information and a genomic approach may prove helpful.

High-throughput RNA sequencing (RNA-seq) is a powerful tool that has been used to identify novel protein-coding and non-coding RNA transcripts involved in the regulation of gene expression (19-24). Recent research has focused on the cardiac long non-coding RNAs (lncRNAs) implicated in cardiac I/R injury (25-29); however, few studies have explored the important role of the spinal cord during focal cardiac I/R. Therefore, the present study was designed to identify the expression patterns of differentially expressed lncRNAs and mRNAs in the spinal cord under normal and cardiac I/R conditions, with the aim to gain a better understanding of the genetic mechanisms underlying the pathogenesis of cardiac I/R injury. The present study also determined the expression levels of various genes in the spinal cord at different time-points during cardiac I/R injury.

\section{Materials and methods}

Animals. A total of 24 male Sprague Dawley (SD) rats aged 8-10 weeks (200-240 g; specific pathogen-free grade; no. 42000600010250) were supplied by the Experimental Animal Research Center of Hubei Province (Hubei, China). The present experiment protocol was approved by the Institutional Ethical Committee of Tongji Hospital, Tongji Medical College, Huazhong University of Science and Technology (Hubei, China; no. TJ-A20150804). All animals were humanely treated according to the National Institutes of Health Guide for the Care and Use of Laboratory Animals (revised 2011) and the Guide for the Care and Use of Laboratory Animals (National Academic Press, USA; revised 2011) (30). Animals were housed in compliance with the Specific Pathogen-Free Animal Criteria, and maintained at a standard temperature of $21-23^{\circ} \mathrm{C}$ and $65 \pm 5 \%$ humidity under a 12 -h light/dark cycle condition, with ad libitum access to artificial feed (food and water).

Myocardial I/R injury model. Surgical procedures to establish the myocardial I/R injury model were performed according to previously described methods (31-33).

\section{Experimental protocol}

Experiment A. A total of $6 \mathrm{SD}$ rats were randomly allocated into 2 groups. The model group $(n=3)$ received $2 \mathrm{~h}$ reperfusion following 30-min occlusion of the left anterior descending coronary artery by pulling the reversible trap (I/R group). The control group $(n=3)$ received the same surgical procedure, without any occlusion of the coronary artery and reperfusion (sham group). T1-T4 spinal cord samples were collected for RNA-seq and reverse transcription-quantitative polymerase chain reaction (RT-qPCR) analysis.
Experiment $B$. A total of $18 \mathrm{SD}$ rats were randomly assigned into 3 groups: i) A control group $(\mathrm{n}=6)$; ii) a $0.5 \mathrm{~h}$ group $(0.5 \mathrm{~h}$ reperfusion following $30 \mathrm{~min}$ ischemia; $\mathrm{n}=6$ ); and iii) a $2 \mathrm{~h}$ group ( $2 \mathrm{~h}$ reperfusion following $30 \mathrm{~min}$ ischemia; $\mathrm{n}=6$ ). T1-T4 spinal cord segments were obtained for RT-qPCR analysis.

Tissue preparation and microarray gene expression analysis. The rats were sacrificed following the completion of the aforementioned experiments. Briefly, upon completion of the experiments, the rats were anesthetized by intraperitoneal injection with $100 \mathrm{mg} / \mathrm{kg}$ body weight ketamine and $10 \mathrm{mg} / \mathrm{kg}$ body weight xylazine (34). Then the rats were quickly decapitated to limit animal suffering and minimize the effects on the experimental results, and the T1-T4 spinal cord segments were immediately removed and frozen with liquid nitrogen for $1 \mathrm{~min}$, then stored at $-80^{\circ} \mathrm{C}$ until required. Total RNA from each animal was quantified using a mirVana miRNA Isolation kit (Ambion; Thermo Fisher Scientific, Inc., Waltham, MA, USA), and RNA integrity was assessed according to the manufacturer's protocol, which included standard denaturing agarose gel electrophoresis (35-37). For RNA-seq, the microarray work was performed by CapitalBio Technology Co. Ltd. (Beijing, China), whereby 6 tissue samples (3 model group samples and 3 control group samples) were used for mRNA and lncRNA microarray analysis (38).

The present study used an Agilent Array platform for microarray analysis. Tissue preparation and microarray hybridization were performed based on the manufacturer's standard protocols (Agilent Technologies, Inc., Santa Clara, CA, USA) with minor modifications. Briefly, the mRNA was purified from the total RNA once the ribosomal RNA was removed using an mRNA-ONLY Eukaryotic mRNA Isolation kit (Epicentre; Illumina, Inc., San Diego, CA, USA). Each sample was then amplified and transcribed into fluorescent complementary RNA (cRNA) along the entire length of the transcripts using a random priming method (39). The labeled cRNAs were hybridized onto the mouse lncRNA Array v2.0 (8x60 K; Arraystar, Inc., Rockville, MD, USA). Then the arrays were scanned using a G2505C Scanner (Agilent Technologies, Inc.).

Bioinformatics analysis. Gene Ontology (GO) annotations were employed to investigate the differentially expressed mRNAs and lncRNAs in the T1-T4 spinal cord segments, according to the GO database (www.geneontology.org/). For the functions of genes and their products, the GO database describes 3 biological functional groups: Biological process, Cellular compartment, and Molecular function. The present study conducted GO functional enrichment analysis on the differentially expressed mRNAs involved in protein-protein interaction (PPI) networks. In addition, the key regulatory pathways in the spinal cord that respond to I/R-induced cardiac injury were also investigated using Kyoto Encyclopedia of Genes and Genomes (KEGG) pathway analysis (www.genome. jp/kegg) and STRING database (string-db.org).

$R T-q P C R$ analysis. The present study extracted total RNA from the upper thoracic spinal cord segments (T1-T4) (40) using TRIzol ${ }^{\circledR}$ reagent (Invitrogen; Thermo Fisher Scientific, Inc.) according to our previous research (35-37). The 
Table I. Primer sequences for reverse transcriptase-quantitative polymerase chain reaction.

A, Upregulated

\begin{tabular}{lcll}
\hline Gene & Length $(\mathrm{bp})$ & \multicolumn{1}{c}{ Forward (5'-3') } & \multicolumn{1}{c}{ Reverse $\left(5^{\prime}-3^{\prime}\right)$} \\
\hline NONRATT025386 & 86 & GGGTCTGGGGTGGGCTAA & GGAGGTTTCTGAGTGGGATGTG \\
NONRATT016113 & 96 & CCACAAGCGTCTCGGGATT & AGCGAAAACAGTCATTTTAACCAA \\
NONRATT018298 & 166 & GACAGTCAACGGAACCAAACTAA & CGTGAACAAAAGCAAGCAAAC \\
NONRATT018300 & 178 & GCCAACAACCAGTAAGAACCAC & CCATACCTTTGCTACTTTGGAGA \\
NONRATT020994 & 150 & GAACGCCACCCCACCAT & CCTTGAAGTCTGAGGCAGGAA \\
\hline
\end{tabular}

B, Downregulated

\begin{tabular}{lcll}
\hline Gene & Length $(\mathrm{bp})$ & Forward $\left(5^{\prime}-3^{\prime}\right)$ & $\left(5^{\prime}-3^{\prime}\right)$ \\
\hline XR_590210.1 & 128 & TTTCAGCCCATCAATGGTTTC & TCCTCAGGAGTGCCCTTTCT \\
NONRATT002188 & 105 & TTCCTACATACTGAGCAACGACC & CCTACCTGTAGCTGCCACTCC \\
XR_589980.1 & 115 & GGATGCCCACTCAAGGGTC & GATGATAAATGCTTGCCCACC \\
XR_598701.1 & 145 & AACAATGGGGACGGTAGTGC & GAAATGAACCTGGGAGAAACG \\
XR_590197.1 & 92 & ACTTCCCTGGATTCTGCTCTG & GGGTCCCCTAACACTATTGCTT \\
\hline GAPDH & 68 & CGCTAACATCAAATGGGGTG & TTGCTGACAATCTTGAGGGAG \\
\hline
\end{tabular}

primers for RT-qPCR were designed based on the lncRNA sequences (Table I), and were synthesized and purified at Invitrogen (Thermo Fisher Scientific, Inc.). The RT reactions were performed using a iScript ${ }^{\mathrm{TM}}$ cDNA Synthesis kit (Bio-Rad Laboratories, Inc., Hercules, CA, USA). RT-qPCR was performed using a ABI StepOnePlusä Multicolor system with the SsoAdvanced ${ }^{\text {TM }}$ Universal SYBR ${ }^{\circledR}$-Green Supermix (Bio-Rad Laboratories, Hercules, Inc.). The PCR thermocycling conditions were as follows: Initial denaturation at $95^{\circ} \mathrm{C}$ for $1 \mathrm{~min}$ followed by 40 cycles of $95^{\circ} \mathrm{C}$ for $15 \mathrm{sec}, 60^{\circ} \mathrm{C}$ for $15 \mathrm{sec}$ and $72^{\circ} \mathrm{C}$ for $45 \mathrm{sec}$. Compared with the averages for the housekeeping gene (GAPDH), the data were quantified using the $2^{-\Delta \Delta C q}$ method for relative fold-change, as described previously (41).

Statistical analysis. Data are expressed as the mean \pm standard error of the mean. The data and statistical graphs were analyzed using the GraphPad Prism v6.02 package (GraphPad Software, Inc., La Jolla, CA, USA). Between-group counts were compared using a Student's t-test (Mann-Whitney U), and the data from three groups were analyzed by one-way analysis of variance followed by Dunn's post hoc test. $\mathrm{P}<0.05$ was considered to indicate a statistically significant difference.

\section{Results}

Characteristics of ischemic myocardial tissues. With regard to the animals in the model group, there were evident cyanotic changes in the myocardium of the occluded area $30 \mathrm{~min}$ post-ischemia, and a reactive hyperemic response after refilling of the left anterior descending coronary artery. With regard to the samples in the model group, examination under a dissecting microscope revealed discoloration of the occluded distal myocardium at the early stage of reperfusion in the infarct region (data not shown).

Expression profiling of lncRNAs in the spinal cord $2 h$ post-cardiac $I / R$. To select possible targets of lncRNAs in the model and control groups, the present study detected up to 16,987 coding transcripts in the T1-T4 spinal cords $2 \mathrm{~h}$ post-reperfusion. A total of 3,621 upregulated and 13,366 downregulated lncRNAs were identified in the spinal cords. On average, 234 lncRNAs were upregulated in the spinal cords of the model group, compared with those in the control group, whereas an average of 7,746 lncRNAs were downregulated ( $>2.0$-fold-change; $\mathrm{P}<0.05$ ). The distributions of the $\log 2$ ratios of the lncRNAs in the model and control samples were nearly identical; Fig. 1 presents the heatmaps of the expression ratios ( $\log 2$ scale) of the lncRNAs in the spinal cords. The top 20 upand downregulated mRNAs are listed in Tables II and III.

Expression profiling of mRNAs in the spinal cord $2 h$ post-cardiac $I / R$. To explore the potential role of mRNAs in the T1-T4 spinal cords $2 \mathrm{~h}$ post-cardiac I/R, the present study determined the expression profiles of mRNAs by high-throughput RNA-seq. Of the 26,466 mRNAs that were quantified using reads per kilobase per million mapped reads (RPKM) values, 3,428 mRNAs were deregulated by 2-fold following I/R-induced cardiac injury, of which 767 mRNAs were upregulated and 2,661 mRNAs were downregulated; Fig. 2 presents the heatmaps of the expression ratios $(\log 2$ scale) of the mRNAs in the spinal cords. The top 20 up- and downregulated mRNAs are listed in Tables IV and V.

Hierarchical clustering analysis of the differentially expressed mRNAs and lncRNAs. Following the determination 

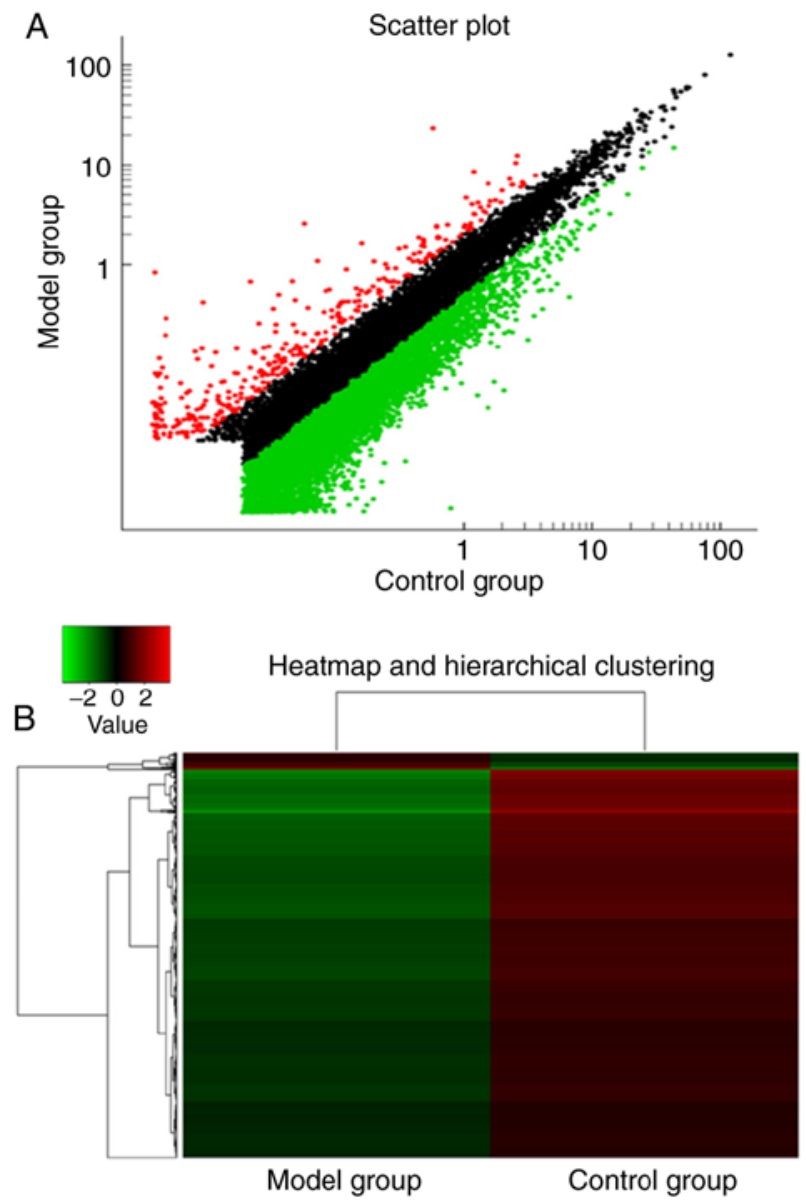

Figure 1. Differential expression of lncRNA in T1-T4 spinal cord sections in the cardiac I/R injury model. (A) Scatter plot comparing global lncRNA expression profiles in the spinal cords of cardiac I/R and control rats. Red indicates upregulated and green indicates downregulated genes. Black indicates the absence of a statistically significant difference, meaning it failed to pass the cutoff values of 1 and -1 in the $\log _{2}$ scale and $\mathrm{P}<0.05$. (B) Heatmap presenting hierarchical clustering of lncRNAs with expression changes of $>2$-fold. In the clustering analysis, up- and downregulated genes are represented by red and green, respectively. I/R, ischemia/reperfusion; lncRNA, long non-coding RNA.

of the expression values of the differentially expressed genes (DEGs), the present study carried out hierarchical clustering analysis on the DEGs. As shown in Figs. 1 and 2, the differentially expressed mRNAs and lncRNAs clearly distinguished the cardiac I/R tissues from the control samples. In the cardiac $\mathrm{I} / \mathrm{R}$ tissues, there were more downregulated genes than upregulated genes (Figs. 1 and 2).

Functionalandpathwayenrichmentanalyses. The significantly enriched GO terms (top 30) were comprised of 16 biological processes, 6 cellular compartments, and 8 molecular functions (Fig. 3). It was revealed that the differentially expressed biological processes in the spinal cords were primarily involved in the serotonin receptor signaling pathway, regulation of protein kinase B signaling, regulation of keratinocyte migration, and skeletal muscle satellite cell differentiation. The significantly enriched pathway terms (top 30) primarily involved KEGG pathways including 'olfactory transduction', 'arachidonic acid metabolism', the 'phosphoinositide 3-kinase-protein kinase B signaling pathway', 'extracellular matrix-receptor interaction', 'cytokine-cytokine receptor interaction' and 'neuroactive ligand-receptor interaction' (Fig. 4). The DEGs were analyzed with GO background significant enrichment, which demonstrated the number of genes associated with biological processes, cellular compartments and molecular functions (Fig. 5).

The results of the biological process analysis revealed that the DEGs involved in PPI networks were mainly enriched in 'neurological system processes' $\left(\mathrm{P}=1.92 \times 10^{-11}\right)$, 'sensory perception' $\left(\mathrm{P}=1.92 \times 10^{-11}\right)$, the 'detection of chemical stimuli' $\left(\mathrm{P}=5.10 \times 10^{-10}\right)$ and 'cell surface receptor signaling pathways' $\left(\mathrm{P}=4.23 \times 10^{-10}\right.$; Fig. 6$)$. A total of 7 cellular components from GO terms were significantly enriched for the DEGs involved in PPI networks: 'Extracellular regions' $(\mathrm{P}=0.02)$, 'membrane parts' $\left(\mathrm{P}=1.54 \times 10^{-5}\right)$, 'extracellular spaces' $\left(\mathrm{P}=1.52 \times 10^{-6}\right)$, 'intrinsic components of the membrane' $\left(\mathrm{P}=1.29 \times 10^{-8}\right)$, the 'cell periphery' $\left(\mathrm{P}=1.76 \times 10^{-7}\right)$, 'integral components of the membrane' $\left(\mathrm{P}=1.61 \times 10^{-8}\right)$ and the 'plasma membrane' $\left(\mathrm{P}=3.22 \times 10^{-7}\right.$; Fig. 7). A total of 10 molecular functions from GO terms were significantly enriched for the DEGs involved in PPI networks: 'Molecular transducer activity' $\left(\mathrm{P}=6.13 \times 10^{-14}\right)$, 'signal transducer activity' $\left(\mathrm{P}=9.42 \times 10^{-14}\right)$, 'receptor activity' $\left(\mathrm{P}=4.77 \times 10^{-14}\right)$, 'signal receptor activity' $\left(\mathrm{P}=4.77 \times 10^{-15}\right)$, 'transmembrane signal receptor activity' $\left(\mathrm{P}=1.31 \times 10^{-15}\right)$, 'serine-type peptidase activity' $\left(\mathrm{P}=9.57 \times 10^{-5}\right)$, 'endopeptidase activity' $(\mathrm{P}=0.02)$, 'olfactory receptor activity' $\left(\mathrm{P}=5.07 \times 10^{-9}\right)$, 'G-protein-coupled receptor activity' $\left(\mathrm{P}=3.03 \times 10^{-14}\right)$ and 'serine-type endopeptidase activity' $\left(\mathrm{P}=1.08 \times 10^{-5}\right)$ (Fig. 8).

$R T-q P C R$ validation of lncRNA expression in the spinal cords $2 \mathrm{~h}$ post-cardiac I/R injury. To validate the reliability of the RNA sequencing results in the rats, the present study analyzed the differentially expressed lncRNAs, including 5 upregulated lncRNAs and 4 downregulated lncRNAs, by RT-qPCR analysis. T1-T4 spinal cord tissues were collected from the control and I/R groups $2 \mathrm{~h}$ post-reperfusion. The expression levels of 4 upregulated lncRNAs (NONRATT025386,NONRATT016113, NONRATT018298 and NONRATT018300) increased significantly in the I/R group when compared with those in the control group, whereas the expression level of one downregulated lncRNA (NONRATT002188) decreased significantly (Fig. 9). The RT-qPCR results for 3 lncRNAs (XR_589980.1, XR_598701.1 and XR_590197.1) were not consistent with the data from the RNA sequencing (XR_589980.1 decreased, and XR_598701.1 and XR_590197.1 increased post-reperfusion when compared with the control; Fig. 10).

Expression levels of 4 lncRNAs in the spinal cord $0.5 \mathrm{~h}$ post-cardiac I/R injury. The present results indicated that the expression levels of the lncRNA NONRATT025386 were significantly upregulated in the $0.5 \mathrm{~h}$ group when compared with the control group, whereas the expression levels of the lncRNAs NONRATT002188 and XR_590197.1 were significantly downregulated in the $0.5 \mathrm{~h}$ group compared with the control group. Furthermore, the lncRNA NONRATT016113 showed no significant difference between the two groups (Figs. 10 and 11).

Expression levels of 9 lncRNAs in the spinal cord at different time-points (0.5 and $2 \mathrm{~h}$ ) following cardiac I/R injury. The 
Table II. Top 20 upregulated lncRNAs in the spinal cord at $2 \mathrm{~h}$ post-reperfusion.

\begin{tabular}{|c|c|c|c|}
\hline LncRNAs (sequence name) & Fold-change (R/N) & RNA length & Chromosome $\log _{2}$ \\
\hline gil672017878|reflXR_345533.2l & 83.01321 & 1,727 & Chr3 \\
\hline NONRATT025386 & 23.99574 & 563 & Chr6 \\
\hline NONRATT024318 & 23.93667 & 473 & Chr6 \\
\hline gil672024701|reflXR_599241.1I & 13.07902 & 728 & Chr10 \\
\hline NONRATT025509 & 10.08656 & 553 & Chr7 \\
\hline gil672017768|reflXR_600487.1I & 9.916187 & 634 & Chr3 \\
\hline NONRATT025839 & 9.860808 & 508 & Chr7 \\
\hline NONRATT023339 & 9.858076 & 706 & Chr5 \\
\hline NONRATT000120 & 9.325455 & 550 & Chr1 \\
\hline NONRATT002260 & 8.604115 & 692 & Chr1 \\
\hline gil672055933|reflXR_592974.1I & 8.306979 & 8,102 & Chr6 \\
\hline uc.126 & 7.209348 & 271 & - \\
\hline gil672086728|reflXR_597427.1I & 6.502431 & 4,903 & Chr20 \\
\hline NONRATT008414 & 6.458688 & 518 & Chr13 \\
\hline NONRATT026470 & 6.452916 & 655 & Chr7 \\
\hline NONRATT015818 & 6.317123 & 255 & Chr2 \\
\hline gil672080453|reflXR_596511.1l & 6.286473 & 1,683 & Chr16 \\
\hline gil672027556|reflXR_340041.2I & 6.236808 & 633 & Chr13 \\
\hline gil672030740|reflXR_598338.1I & 6.169331 & 1,360 & Chr18 \\
\hline NONRATT016237 & 6.087859 & 817 & Chr2 \\
\hline
\end{tabular}

Values are presented as fold-changes in the reperfusion groups (reperfusion $2 \mathrm{~h}$ ) over the control group $(\mathrm{N}>2.0$-fold; $\mathrm{P}<0.05)$. lncRNA, long non-coding; $\mathrm{Chr}$, chromosome; $\mathrm{R} / \mathrm{N}$, reperfusion/normal.

Table III. Top 20 downregulated lncRNAs in the spinal cord at $2 \mathrm{~h}$ post-reperfusion.

\begin{tabular}{|c|c|c|c|}
\hline LncRNAs (sequence name) & Fold-change (R/N) & RNA length & Chromosome $\log _{2}$ \\
\hline NR_130708.1 & -27.7049 & 1,379 & Chr3 \\
\hline NONRATT028627 & -25.2873 & 410 & Chr8 \\
\hline NONRATT021959 & -22.8492 & 709 & Chr4 \\
\hline gil672034655|ref|XR_590005.1I & -21.8020 & 1,290 & Chr1 \\
\hline NONRATT023191 & -19.8345 & 1,977 & Chr5 \\
\hline NONRATT025830 & -19.4635 & 525 & Chr7 \\
\hline NONRATT027253 & -19.4441 & 1,233 & Chr7 \\
\hline NONRATT023189 & -19.2427 & 2,086 & Chr5 \\
\hline NONRATT014248 & -18.4873 & 1,049 & Chr19 \\
\hline NONRATT008322 & -17.5179 & 451 & Chr13 \\
\hline NONRATT014862 & -16.4839 & 619 & Chr2 \\
\hline NONRATT016808 & -16.4007 & 518 & Chr2 \\
\hline NONRATT017256 & -16.2487 & 786 & Chr20 \\
\hline NONRATT011649 & -15.8013 & 566 & Chr16 \\
\hline gil672021532|ref|XR_347699.2l & -15.494 & 537 & Chr7 \\
\hline NONRATT024978 & -14.3807 & 1,486 & Chr6 \\
\hline NONRATT012913 & -13.9501 & 338 & Chr17 \\
\hline NONRATT004220 & -13.7216 & 2,171 & Chr10 \\
\hline NONRATT018550 & -13.4908 & 365 & Chr3 \\
\hline NONRATT008489 & -13.4256 & 1,076 & Chr13 \\
\hline
\end{tabular}

Values are present as fold-changes in the reperfusion groups (reperfusion $2 \mathrm{~h}$ ) over the control group $(\mathrm{N}>2.0$-fold; $\mathrm{P}<0.05)$. lncRNA, long non-coding; Chr, chromosome; R/N, reperfusion/normal. 

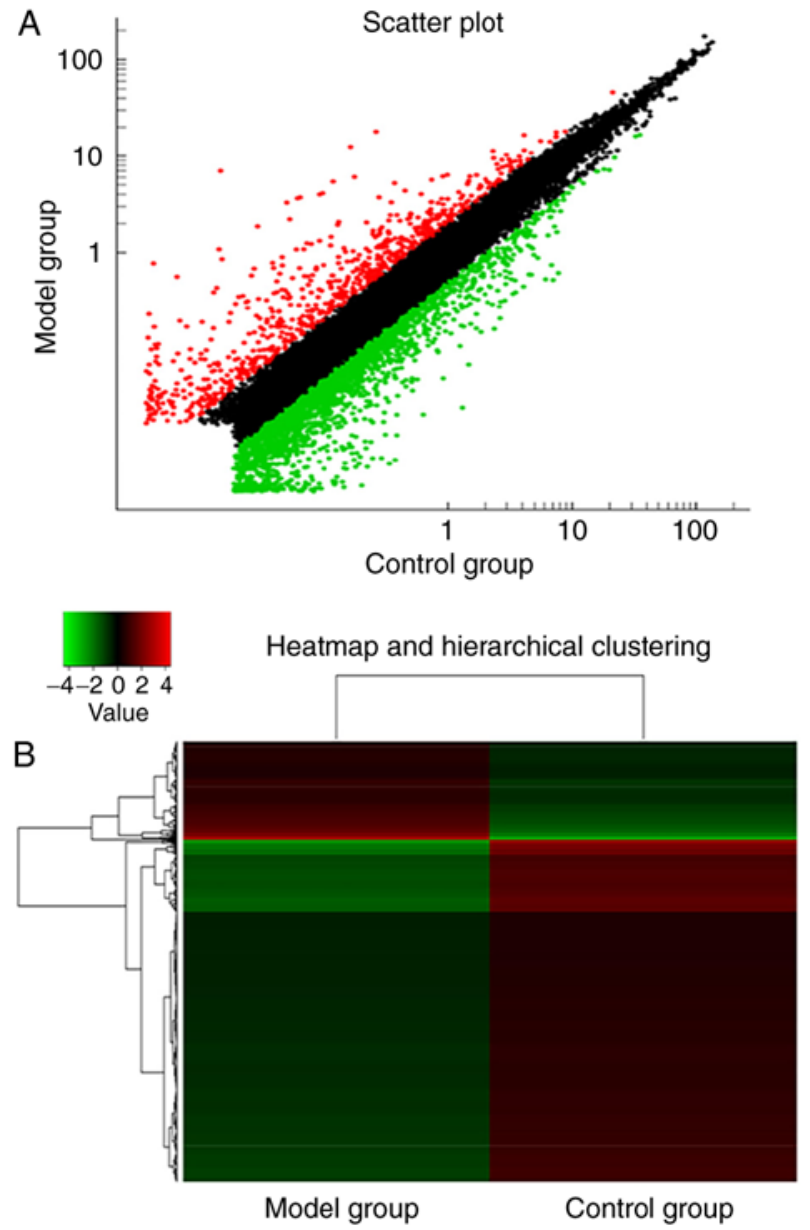

Figure 2. Differential expression of mRNA genes in the T1-T4 spinal cord sections in the cardiac I/R injury model. (A) Scatter plot comparing global mRNA gene expression profiles in the spinal cords of cardiac $\mathrm{I} / \mathrm{R}$ and control rats. Red indicates upregulated and green indicates downregulated genes. Black indicates the absence of a statistically significant difference, meaning it failed to pass the cutoff values of 1 and -1 in the $\log _{2}$ scale and false discovery rate (corrected P-value) $<0.05$. (B) Heatmap presenting hierarchical clustering of mRNAs with expression changes of $>2$-fold. In the clustering analysis, up- and downregulated genes are represented by red and green, respectively. I/R, ischemia/reperfusion.

present study collected samples from spinal cord tissues at 0.5 and $2 \mathrm{~h}$ post-cardiac I/R injury for RT-qPCR validation. The results indicated that the expression levels of the lncRNA NONRATT025386 were significantly upregulated in the 0.5 and $2 \mathrm{~h}$ groups compared with the control group. In addition, the expression levels of NONRATT016113, NONRATT018298 and NONRATT018300 were also significantly increased in the $2 \mathrm{~h}$ group, but not at $0.5 \mathrm{~h}$, compared with the control group (Figs. 9-11). By contrast, the expression levels of the lncRNA NONRATT002188 were significantly downregulated in the 0.5 and $2 \mathrm{~h}$ groups when compared with the control group (Figs. 9-11).

\section{Discussion}

With regard to ischemic cardiac tissues, previous research has focused on multiple signaling pathways that regulate the critical balance between cell death and survival during cardiac I/R injury (42-47). The present study, to the best of our knowledge, for the first time provides evidence that suggests that many DEGs, pathways and biological processes of the T1-T4 spinal cord are implicated in myocardial I/R. Based on high-throughput RNA seq, 16,987 lncRNAs in the T1-T4 spinal cord tissues were identified, of which 3,621 were upregulated and 13,366 were downregulated $(>2.0$-fold-change; $\mathrm{P}<0.05)$. Among the 26,466 mRNAs that were quantified using RPKM values, 3,428 were deregulated by 2 -fold following I/R-induced cardiac injury, of which 767 were upregulated and 2,661 were downregulated. According to these results, some differentially expressed lncRNAs were verified by RT-qPCR analyses.

Previous studies have shown that the spinal cord serves an important role in the pathogenesis of cardiac disease (48-51). The present study used a virally mediated trans-synaptic tracing method, by injecting the PRV virus into the rat heart and kidney, and these viruses were subsequently found in the lateral medial column of the spinal cord in the corresponding segment $(12,52)$. This revealed the characteristics of the transcriptome in the T1-T4 spinal cord following cardiac I/R injury and the specific spinal segment that innervates the heart serves a significant role in cardiac I/R injury. Cheng et al (53) reported that melatonin regulation of the transcriptome was associated with the reversal of morphine tolerance by transcriptomic analysis of the L5-S3 segmental spinal cord. Mohrman et al (54) revealed the spinal cord transcriptomic and metabolic patterns in a excitotoxic injection injury model of syringomyelia. Niu et al (55) demonstrated the upregulation of tumor necrosis factor (TNF)- $\alpha$ in spinal cord neurons during coronary artery occlusion in rats, suggesting that TNF- $\alpha$ in the spinal cord may be associated with the nociception initiated by acute myocardial ischemia/infarction. Schulz et al (56) reported that connexin 43 in the spinal cord serves an important role in providing protection from cardiac $\mathrm{I} / \mathrm{R}$ injuries. It is well known that myocardial ischemia creates an autonomic nervous system imbalance, and can trigger cardiac arrhythmias (57,58). Howard-Quijano et al (59) indicated that neuromodulation by spinal cord stimulation (SCS), in which a 4-pole lead was placed percutaneously in the T1-T4 epidural space, attenuated local cardiac sympathoexcitation from ischemia-induced increases in afferent signaling, reduced ventricular arrhythmias and improved myocardial function during acute ischemia. Liao et al (60) reported that chronic thoracic SCS at the T1-T3 level induced significant remodeling of cardiac sympathetic innervation over the peri-infarct and infarct regions, and was associated with improved left ventricular function and reduced myocardial norepinephrine spillover. The present study revealed that the differential expression of certain mRNAs and lncRNAs in the spinal cord affects the myocardial ischemic regions, suggesting that in the spinal T1-T4 segment these genes are involved in the response to cardiac injury. Although the functions of mRNAs and lncRNAs in the spinal cord are unclear, the present findings provide a novel paradigm for cardioprotection against I/R-induced myocardial injury.

The present results also revealed that some mRNAs in the spinal cord, including chemokine $\mathrm{C}-\mathrm{X}-\mathrm{C}$ motif ligand 1 (CXCL1), regulatory factor X4 (RFX4), WNT10a and interleukin (IL)-6, were differentially expressed following cardiac I/R. Haider et al (61) reported that the angiogenic potential of the mononuclear cell (MNC) secretome is 
Table IV. Top 20 upregulated mRNAs in the spinal cord at $2 \mathrm{~h}$ post-reperfusion.

\begin{tabular}{|c|c|c|c|}
\hline mRNAs (sequence name) & Fold-change (R/N) & GENE_SYMBOL & GENE_NAME \\
\hline A_64_P004112 & 25.97118 & - & - \\
\hline A_64_P151353 & 25.46518 & Acsm5 & Acyl-CoA synthetase medium-chain family member 5 \\
\hline A_64_P181171 & 21.23528 & - & - \\
\hline A_64_P149280 & 21.07919 & Vegfb & Vascular endothelial growth factor B \\
\hline A_64_P273771 & 15.23514 & - & - \\
\hline A_64_P260129 & 14.28584 & Gzmc & Granzyme C \\
\hline A_44_P122912 & 13.21478 & Ces1c & Carboxylesterase $1 \mathrm{C}$ \\
\hline A_44_P553341 & 13.01391 & Lrfn5 & $\begin{array}{l}\text { Leucine rich repeat and fibronectin type III domain } \\
\text { containing } 5\end{array}$ \\
\hline A_64_P094055 & 10.5432 & - & - \\
\hline A_44_P401110 & 10.10015 & Prss40 & 'Protease, serine, 40' \\
\hline A_64_P147769 & 8.814655 & Gucy $1 b 2$ & 'Guanylate cyclase 1 , soluble, $\beta 2$ ' \\
\hline A_64_P082082 & 8.515041 & - & - \\
\hline A_64_P045902 & 8.093776 & - & - \\
\hline A_64_P118367 & 8.069224 & Lrrd1 & Leucine-rich repeats and death domain containing 1 \\
\hline A_64_P156605 & 7.85615 & - & - \\
\hline A_64_P135295 & 7.737585 & $\mathrm{Cd} 300 \mathrm{c}$ & CD300c molecule \\
\hline A_64_P042127 & 7.403613 & Akr1c3 & 'Aldo-keto reductase family 1, member C3' \\
\hline A_44_P445575 & 7.245778 & $\operatorname{Irx} 2$ & Iroquois homeobox 2 \\
\hline A_64_P162476 & 7.220482 & Art1 & ADP-ribosyltransferase 1 \\
\hline A_64_P186630 & 7.156018 & Vom2r60 & 'Vomeronasal 2 receptor, 60' \\
\hline
\end{tabular}

Values are fold-changes in the reperfusion groups (reperfusion $2 \mathrm{~h}$ ) over the control group $(\mathrm{N}>2.0$-fold; $\mathrm{P}<0.05$ ). $\mathrm{R} / \mathrm{N}$, reperfusion/normal.

Table V. Top 20 downregulated mRNAs in the spinal cord at $2 \mathrm{~h}$ post-reperfusion.

mRNAs (sequence name) Fold-change (R/N) GENE_SYMBOL

GENE_NAME

\begin{tabular}{lccl}
\hline A_64_P141763 & -38.1959 & Muc16 & 'Mucin 16, cell surface associated' \\
A_42_P473398 & -33.0016 & Cxcl1 & Chemokine (C-X-C motif) ligand 1 \\
A_44_P550907 & -29.4102 & RGD1306750 & LOC362451 \\
A_44_P702019 & -23.3124 & Rfx4 & 'Regulatory factor X, 4 (influences HLA class II expression)' \\
A_64_P021855 & -22.6481 & LOC499643 & Similar to hypothetical protein FLJ25371 \\
A_44_P367541 & -21.9947 & Olr671 & Olfactory receptor 671 \\
A_64_P036090 & -20.4897 & - & \\
A_44_P371339 & -20.0377 & IL6 & Interleukin 6 \\
A_64_P141762 & -19.8627 & - & \\
A_64_P018554 & -19.1504 & - & \\
A_64_P101228 & -16.1995 & Tas2r120 & 'Taste receptor, type 2, member 120' \\
A_44_P563447 & -15.8884 & Wnt10a & 'Wingless-type MMTV integration site family, member 10A' \\
A_44_P698466 & -15.406 & Lrrtm2 & Leucine rich repeat transmembrane neuronal 2 \\
A_44_P461456 & -15.3963 & Pr14a1 & 'Prolactin family 4, subfamily a, member 1' \\
A_44_P378749 & -14.7924 & LOC100912608 & Homeobox protein Hox-A10-like \\
A_44_P547892 & -14.7229 & Olr1345 & Olfactory receptor 1345 \\
A_64_P001947 & -14.5408 & - & \\
A_64_P009237 & -14.3488 & - & \\
A_64_P029912 & -13.3859 & Cldnd2 & Claudin domain containing 2 \\
A_64_P074460 & -13.1395 & - & \\
\hline
\end{tabular}

Values are fold-changes in the reperfusion groups (reperfusion $2 \mathrm{~h}$ ) over the control group $(\mathrm{N}>2.0$-fold; $\mathrm{P}<0.05$ by analysis of variance). $\mathrm{R} / \mathrm{N}$, reperfusion/normal. 


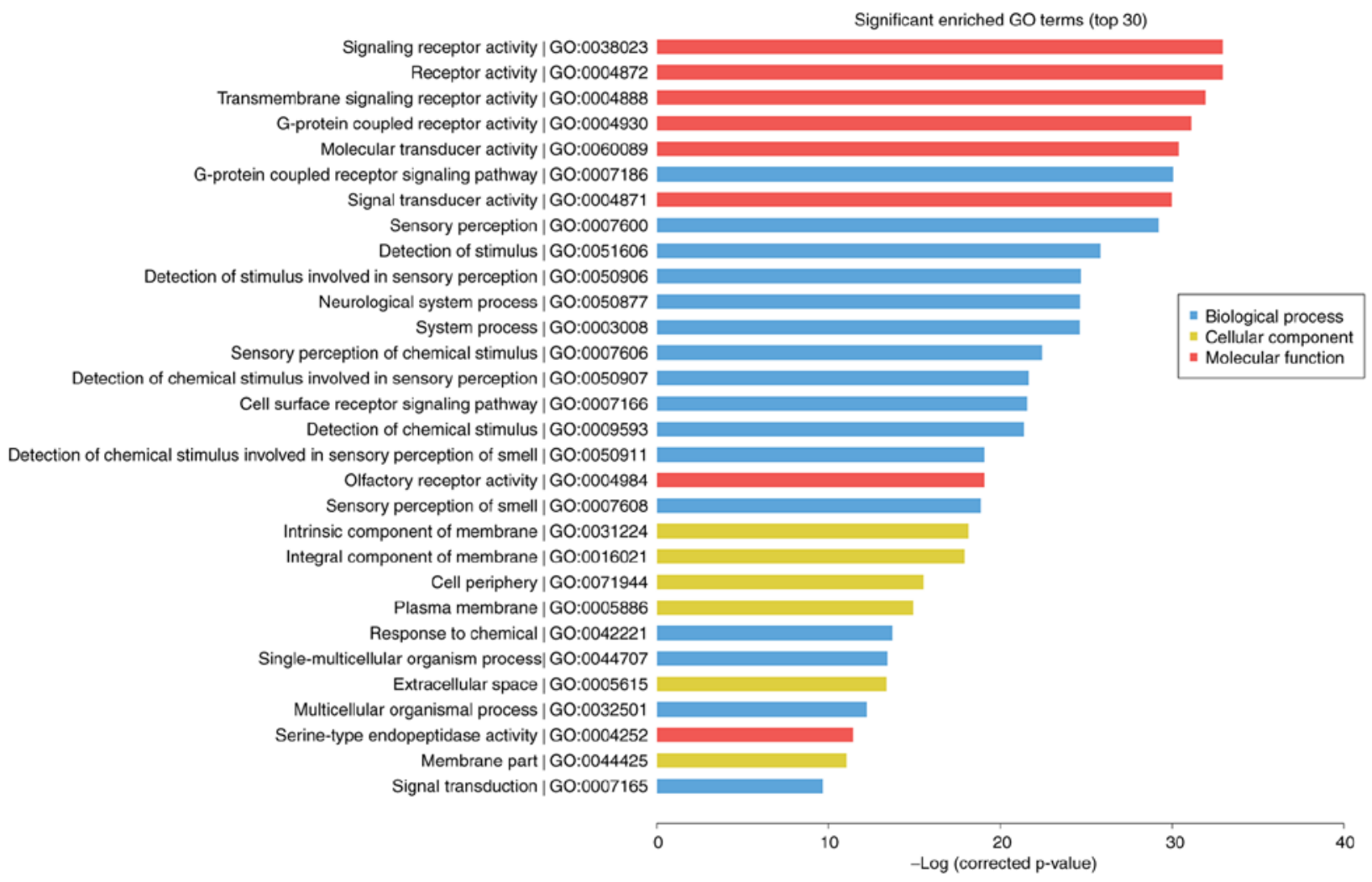

Figure 3. Top 30 significantly enriched GO terms as determined by GO annotation analysis. The blue bars represent biological process classification; the yellow bars represent cellular components; and the red bars represent molecular function. GO, Gene Ontology.

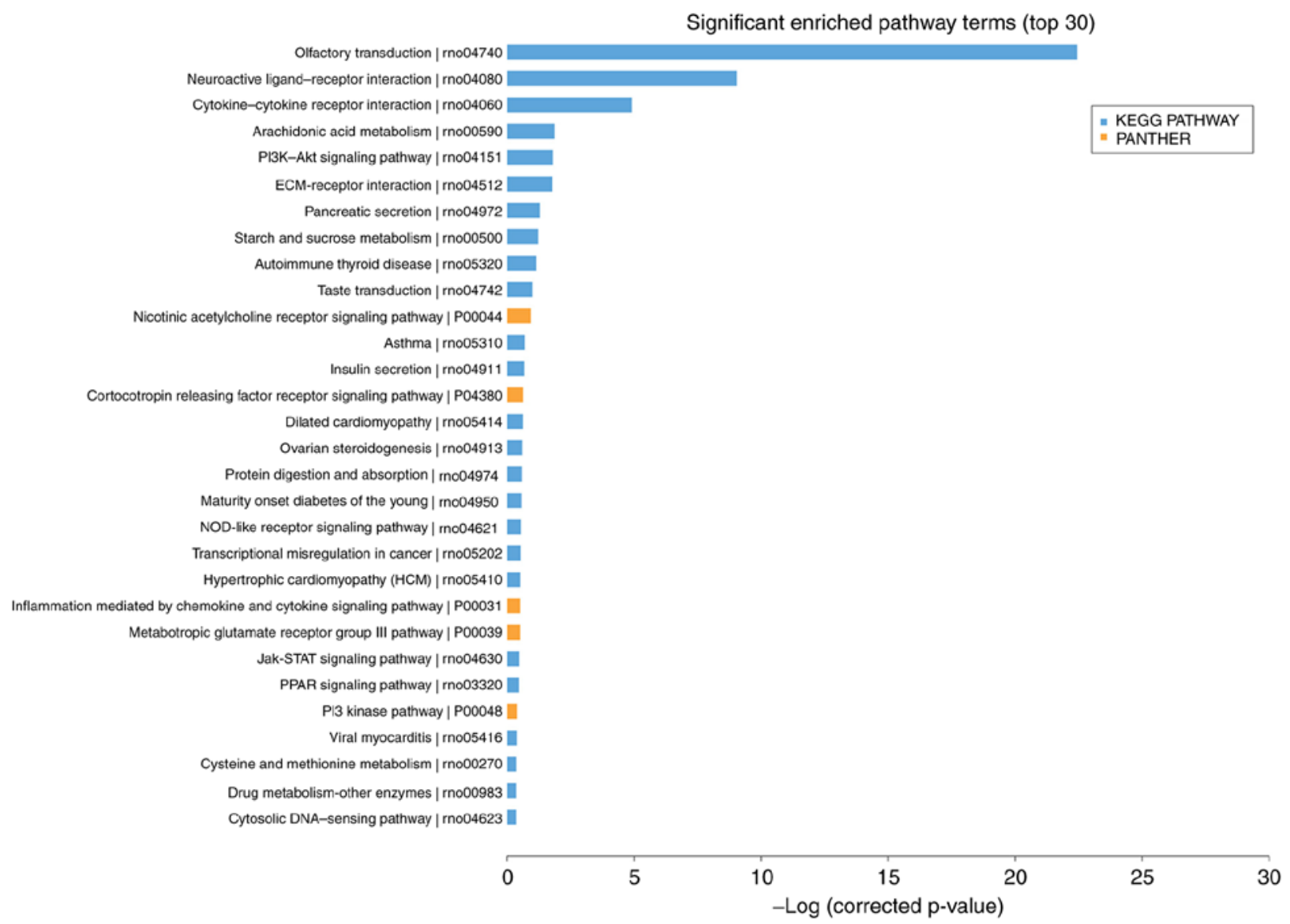

Figure 4. Top 30 significantly enriched pathway terms determined by Gene Ontology annotation analysis. Blue bars represent the KEGG pathway and orange bars represent PANTHER. KEGG, Kyoto Encyclopedia of Genes and Genomes. 


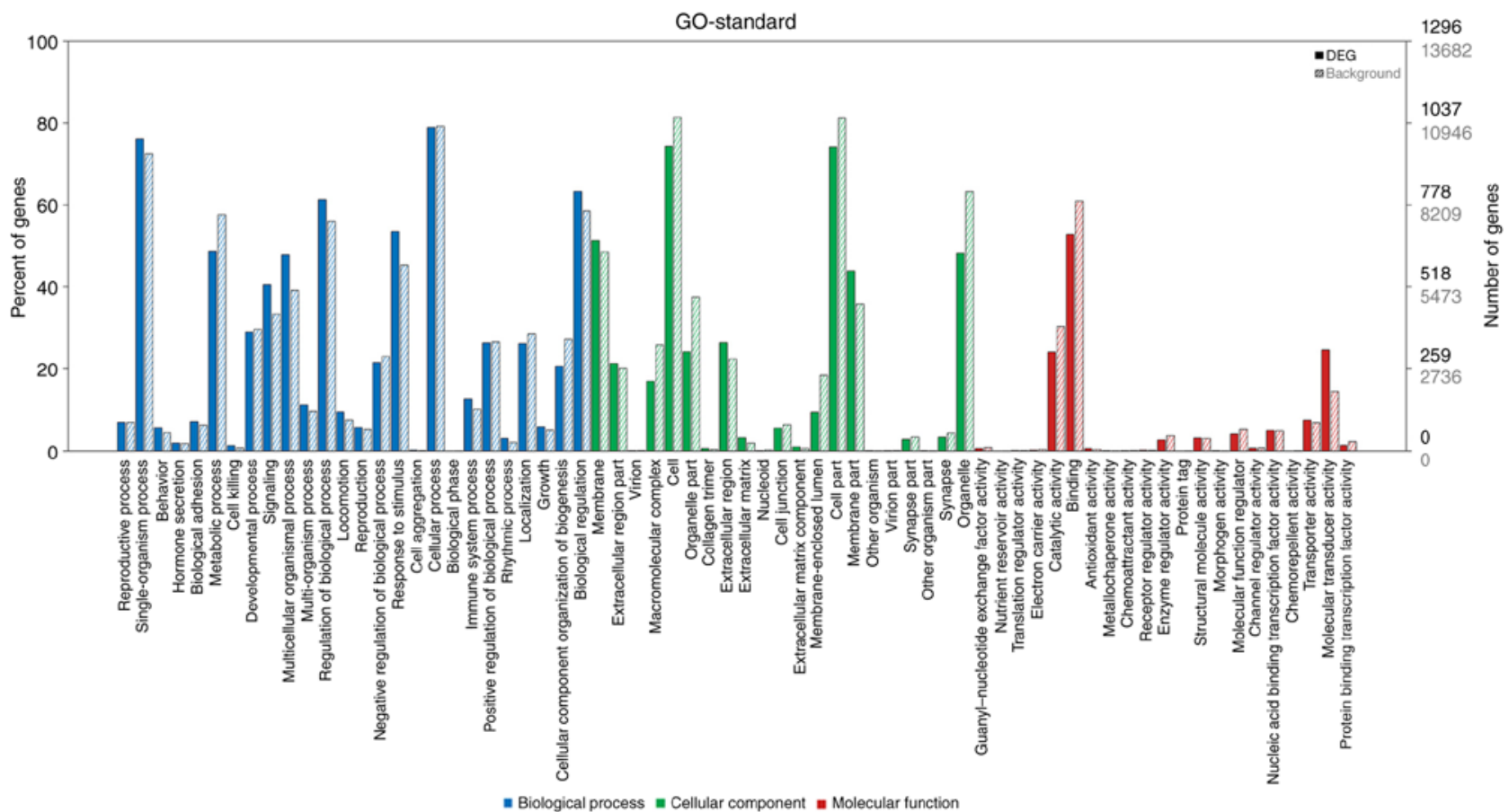

Figure 5. Differentially expressed genes analyzed by GO background significant enrichment. Solid bars represent the target gene set and slashed bars represent the gene set. GO, Gene Ontology.

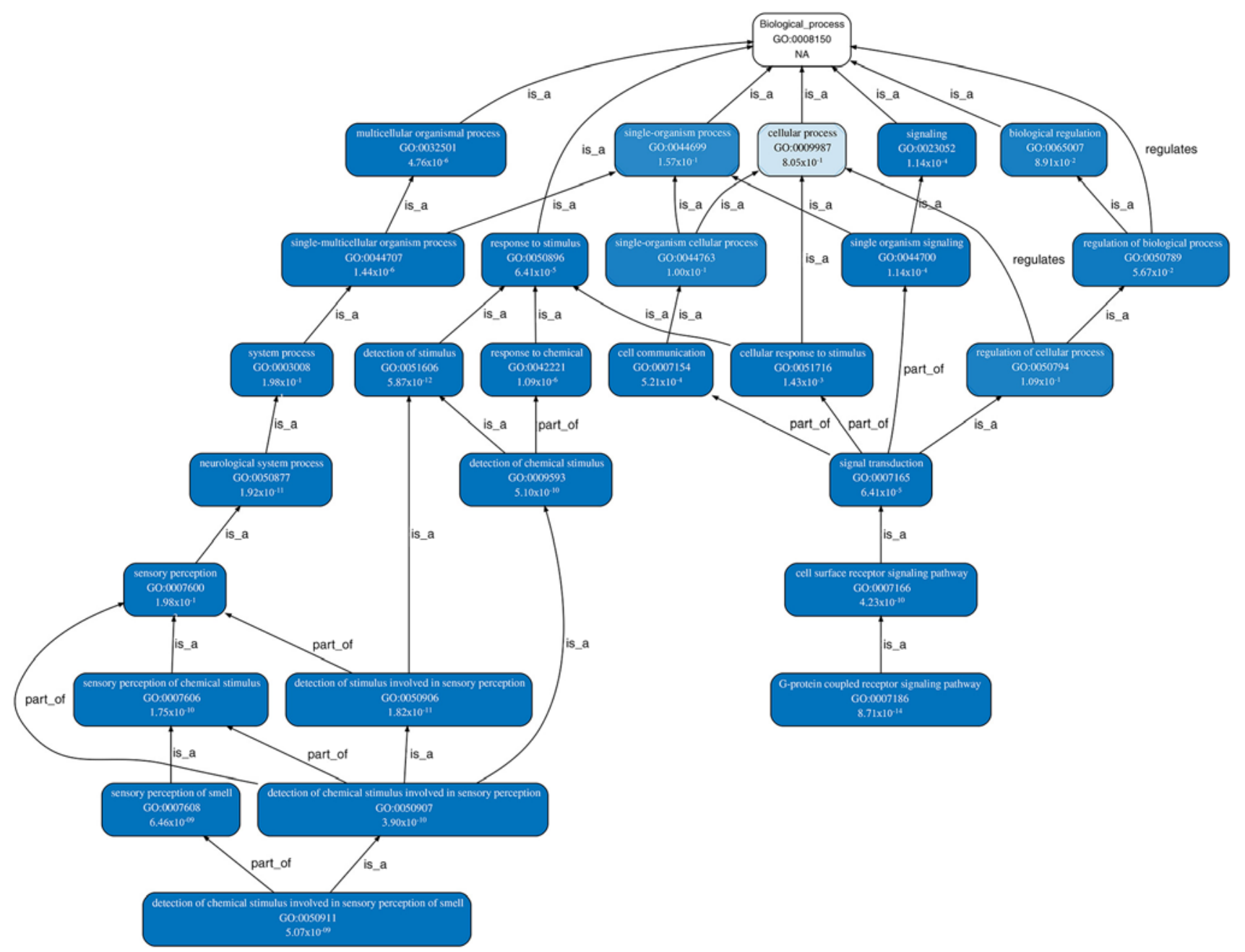

Figure 6. Enrichment GO hierarchy of Biological Process. The GO terms enriched for the differentially expressed genes involved in the protein-protein interaction network constructed from the STRING database. GO, Gene Ontology. 


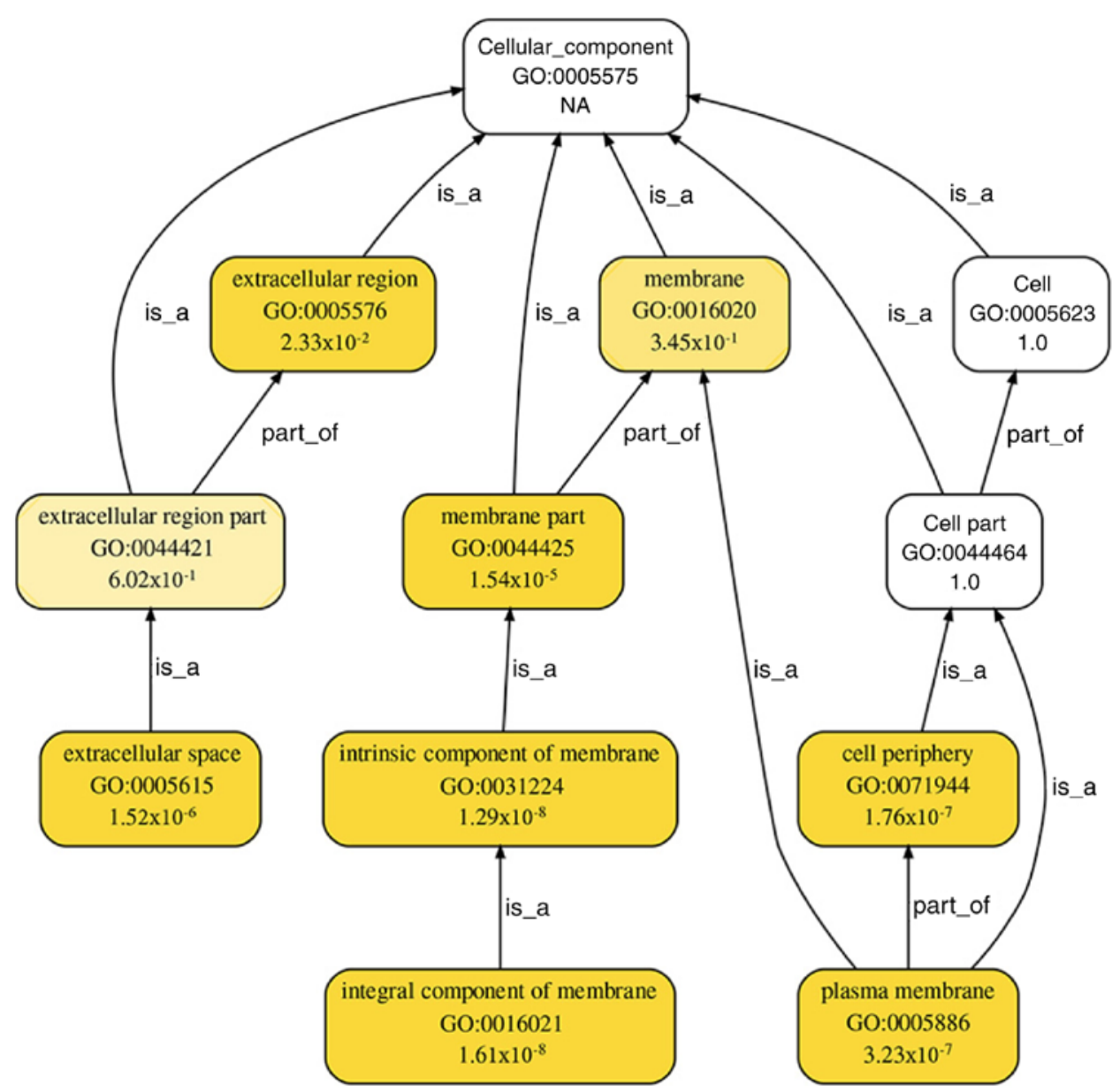

Figure 7. Enrichment GO hierarchy of Cellular Component. A total of 7 Cellular Components from the GO terms were significantly enriched for the differentially expressed genes involved in the protein-protein interaction network. GO, Gene Ontology.

regulated by CXCL-1 upregulation in spinal cord tissue, and factors in the MNC secretome may mitigate the pathophysiological processes of secondary damage following spinal cord injury, and may also improve functional outcomes in rats. Ashique et al (62) reported that the spinal cords of RFX4 mutants were correlated with defects in patterning and cilia formation, suggesting that RFX4 is a regionally specific transcriptional regulator of Sonic hedgehog signaling during the development of the central nervous system. Zhao et al (63) demonstrated that hyperbaric oxygen (HBO) reverses Wnt-10a upregulation induced by chronic constriction (CCI) injury in the dorsal root ganglion (DRG), spinal cord and hippocampus, suggesting that $\mathrm{HBO}$ attenuates $\mathrm{CCI}$-induced rat neuropathic pain and inflammatory responses, potentially through regulation of the Kindlin-1/Wnt-10a signaling pathway. Although the detailed functions of many mRNAs from spinal cords are not fully understood, the present results provide novel insight into the molecular mechanisms underlying cardiac I/R injury.

It is well known that regulations of gene expression are varied over the time course (64-66). Our previous research associated with Itchy E3 ubiquitin protein ligase demonstrated that gene expression was significantly different in the C5-C8 spinal cord at 0.5 and $2 \mathrm{~h}$ following compound 48/80 injection when compared with the control group (36). Similar to the above method, we also screened key genes in myocardial tissues under 30 min cardiac ischemia following $2 \mathrm{~h}$ reperfusion compared with the sham group (67). Li et al (68) also indicated that impairment of sensory nerves with significant reductions in CGRP and SP in the DRG, ventricular myocardium and serum may be associated with an increase in myocardial vulnerability in acute cardiac I/R injury in diabetic rats. It was revealed that the injury was relatively evident at $2 \mathrm{~h}$ post-myocardial reperfusion, which may be considered as an acute cardiac I/R injury. Notably, this time point could be equivalent to the patients who received early percutaneous coronary intervention following myocardial infarction $(69,70)$. Therefore, the present study chose 0.5 and $2 \mathrm{~h}$ post-reperfusion as the different time points of cardiac reperfusion injury. The present study revealed that there are significant differences in lncRNA and mRNA expression patterns at different time points of myocardial I/R, suggesting that the neural modulation of cardiac I/R injury may be temporal- and spatial-dependent.

In particular, our previous study also demonstrated that proton magnetic resonance spectroscopy was able to simultaneously detect and quantify the absolute concentrations of multiple metabolites within the spinal cord underlying $\alpha$-Me-5-HT-evoked pruritus (71). Using the above method, we can also detect the changes of various metabolites in the spinal cord following cardiac I/R injury, which may deepen our understandings of the pathophysiology and pharmacological therapies for acute myocardial infarction. 


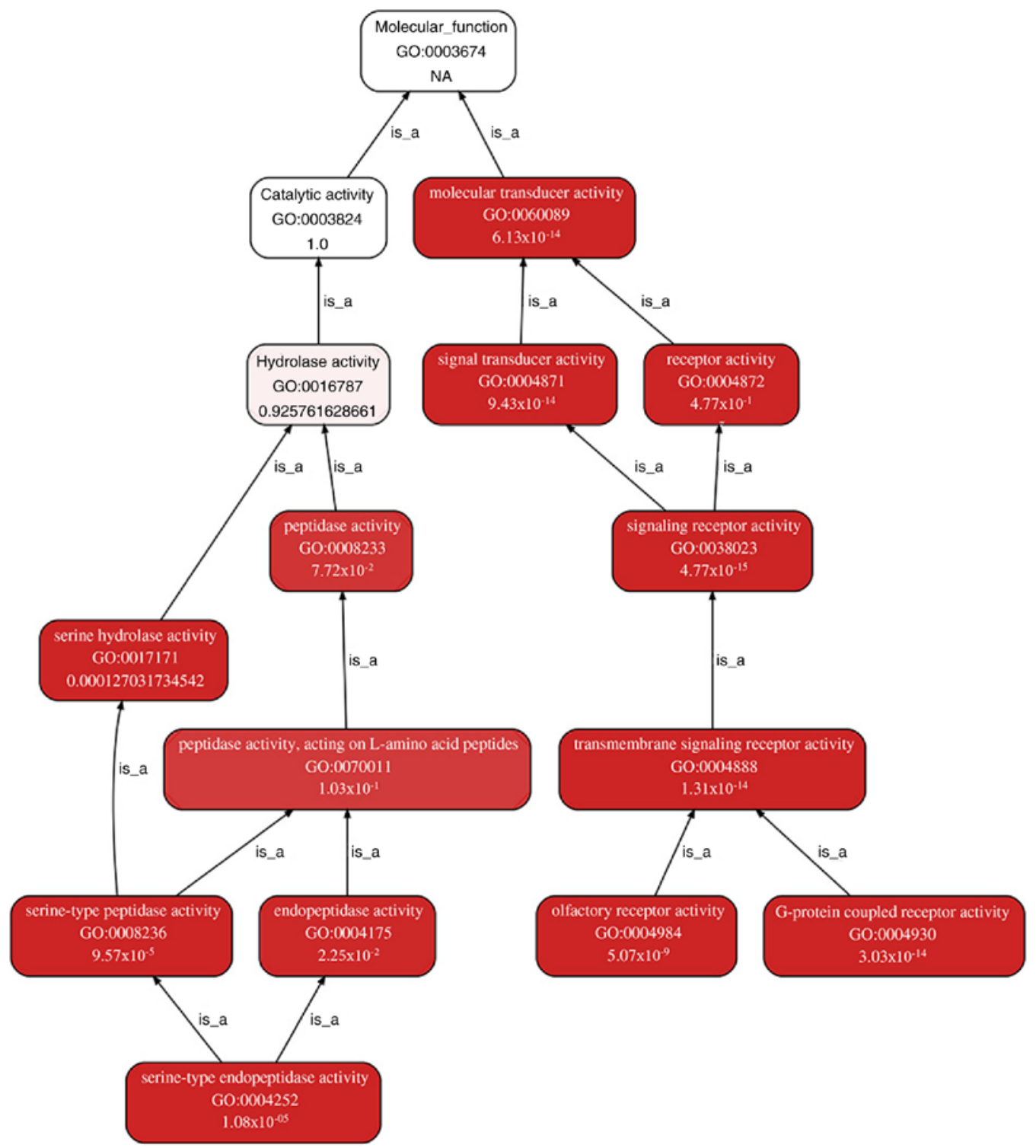

Figure 8. Enrichment GO hierarchy of Molecular Function. A total of 10 molecular functions from GO terms were significantly enriched for the differentially expressed genes involved in the protein-protein interaction network. GO, Gene Ontology.

A NONRATTO25386

NONRATT016113

NONRATT018298

NONRATT018300

NONRATT020994
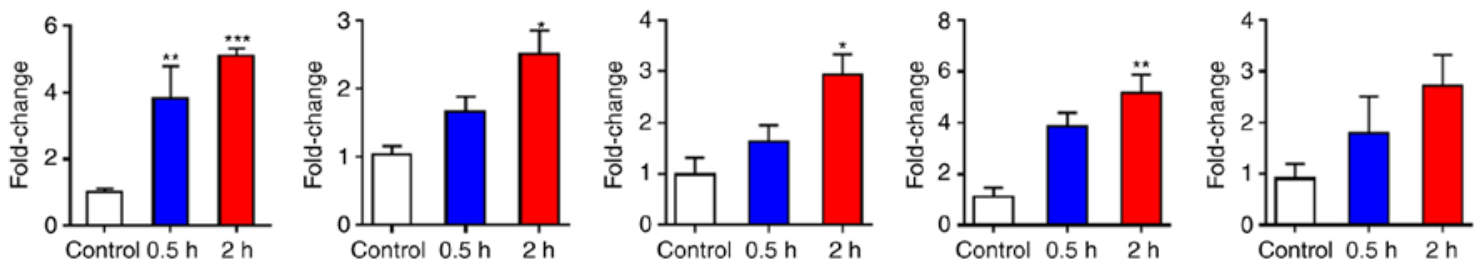

B NONRATT002188

gi|672034598|ref|XR_589980.1
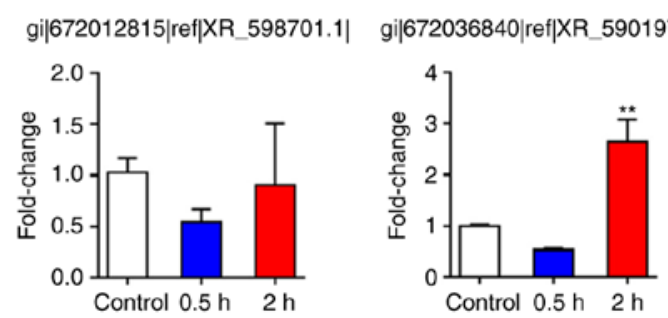

Figure 9. Expression levels of 9 lncRNAs in the spinal cord (T1-T4) at different time-points ( 0.5 and $2 \mathrm{~h})$ following cardiac ischemia/reperfusion injury. The expression levels of NONRATT025386, were upregulated in the 0.5 and $2 \mathrm{~h}$ groups. (A) The expression levels of NONRATT016113, NONRATT018298 and NONRATT018300 were only significantly upregulated in the $2 \mathrm{~h}$ group. (B) The expression levels of lncRNA NONRATT002188 were significantly downregulated in the 0.5 and $2 \mathrm{~h}$ groups. ${ }^{*} \mathrm{P}<0.05,{ }^{* *} \mathrm{P}<0.01$ and ${ }^{* * *} \mathrm{P}<0.001$ vs. control. lncRNA, long non-coding RNA. 


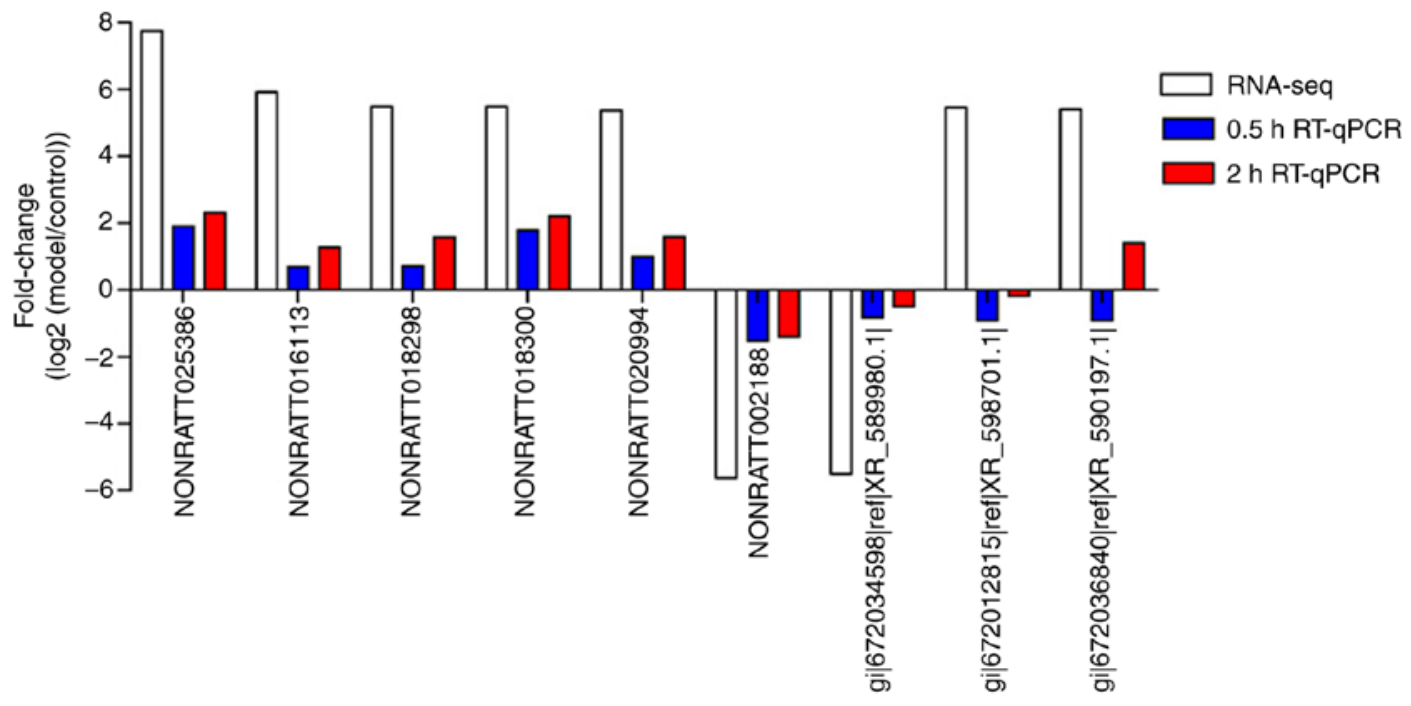

Figure 10. Validation of the differential expression of lncRNAs in spinal cord sections at different time-points $(0.5$ and 2 h) following cardiac ischemia/reperfusion injury. A total of 7 upregulated lncRNAs and 2 downregulated lncRNAs were confirmed by RT-qPCR. The levels of lncRNAs were normalized to GAPDH and expressed as fold-changes compared with the sham group. RT-qPCR, reverse transcription-quantitative polymerase chain reaction; lncRNA, long non-coding RNA.

A

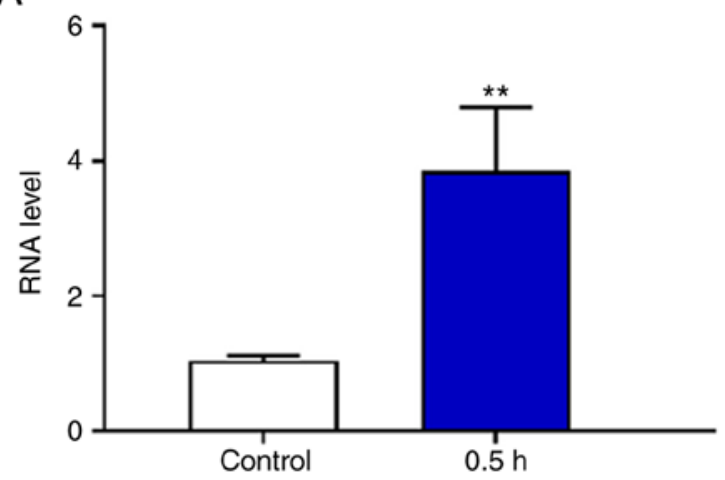

C

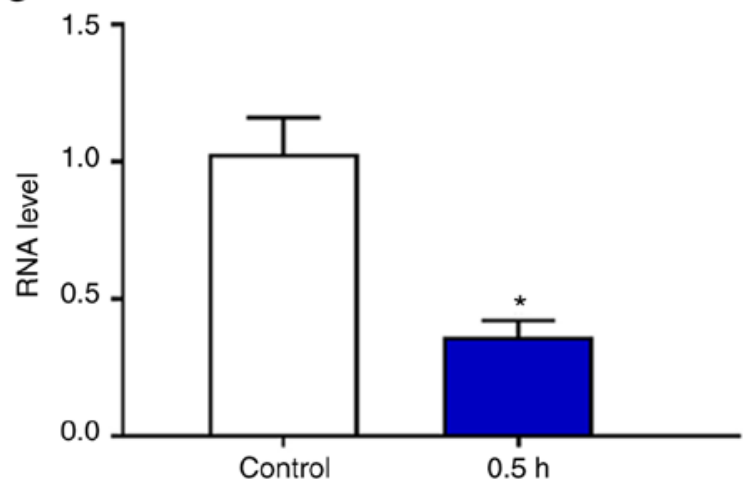

B

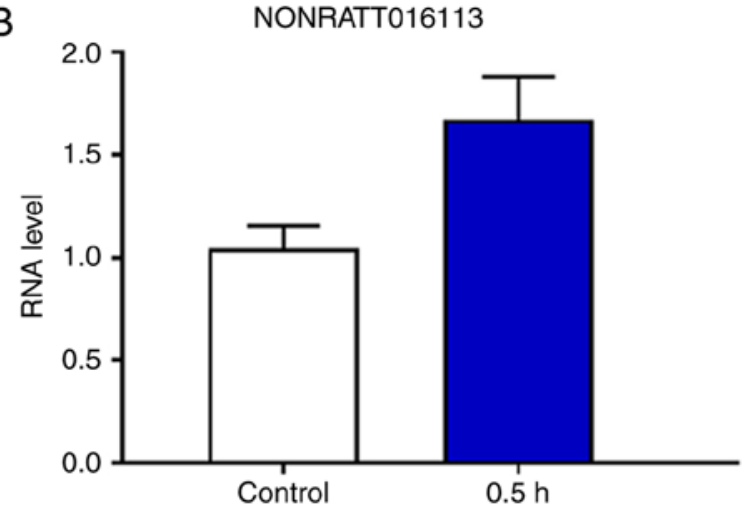

D

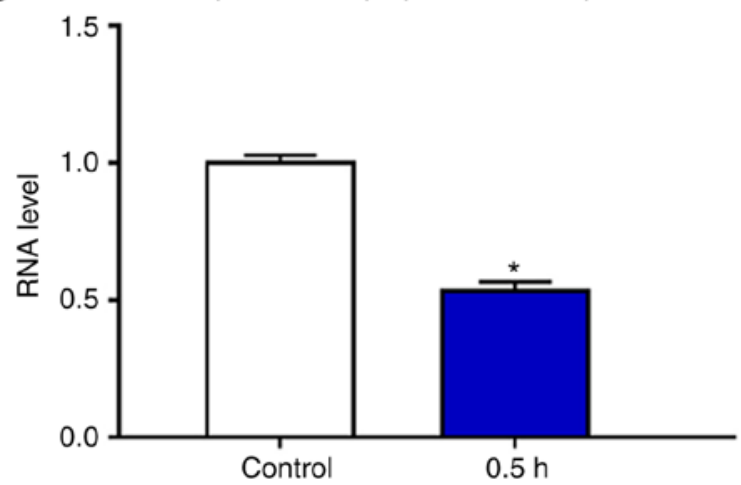

Figure 11. Reverse transcription-quantitative polymerase chain reaction confirmation of 3 deregulated lncRNAs in the rat spinal cord sections in the ischemia/reperfusion injury model. The expression levels of the lncRNA (A) NONRATT025386 was significantly upregulated in the 0.5 h group and the (B) lncRNA NONRATT016113 showed no significance between the two groups. The expression levels of the lncRNAs (C) NONRATT002188 and (D) gil672 036840|reflXR_590197.1l were significantly downregulated. Mann-Whitney test. ${ }^{*} \mathrm{P}<0.05$ and ${ }^{* *} \mathrm{P}<0.01$ vs. control. lncRNA, long non-coding RNA.

The present study screened several differentially expressed mRNAs under cardiac I/R injury. In the future, whether the proteins encoded by the mRNAs are consistent with these mRNAs will be verified by immunoblotting. If so, the effects on cardiac I/R injury may be observed by activating or silencing the expression of one specific mRNA. Li et al (68) revealed that the regulation of the spinal cord served a significant role under cardiac I/R injury in diabetic neuropathic rats. Thus, it can be hypothesized that intervention on the spinal cord may have an important influence on cardioprotection in the future. 
The present study used high-throughput RNA seq, coupled with RT-qPCR analysis, to demonstrate that the expression profiles of lncRNAs and mRNAs in spinal cords differed markedly between the control and $2 \mathrm{~h}$ groups, and ultimately identified 7,980 differentially expressed (>2-fold) lncRNAs (234 upregulated and 7,746 downregulated) and 3,428 mRNAs (767 upregulated and 2,661 downregulated). The expression patterns of several lncRNAs were confirmed by RT-qPCR. The results also indicated that the expression levels of the lncRNA NONRATT025386 were significantly upregulated in the 0.5 and $2 \mathrm{~h}$ groups compared with the control group, whereas the expression levels of NONRATT016113, NONRATT018298 and NONRATT018300 were significantly increased in the $2 \mathrm{~h}$ group when compared with the control group, although there was no statistically significant difference between the expression levels in the $0.5 \mathrm{~h}$ and control groups. Furthermore, the expression levels of the lncRNA NONRATT002188 were significantly downregulated in the 0.5 and $2 \mathrm{~h}$ groups compared with the control group.

In conclusion, this study revealed that high-throughput RNA seq can facilitate the systematic exploration of gene expression on a genome-wide scale, and can be used to investigate DEGs and lncRNA expression patterns in the spinal cords of rats during I/R-induced cardiac injury. In the search for better treatments for cardiac I/R injury, expanded sets of differentially expressed mRNAs and lncRNAs may prove very useful for identifying novel therapeutic targets.

\section{Acknowledgements}

The authors would like to thank CapitalBio Technology Co., Ltd. (Beijing, China) for their technical advice and Dr Taotao Liu (Department of Anesthesiology, Peking University Third Hospital, Peking University, Beijing, China) for his contribution to image acquisition.

\section{Funding}

The present study was supported by grants from National Natural Science Foundation of P.R. China (grant nos. 81670240, 81873467 and 81770283), National Natural Science Foundation of Hubei Province (grant no. 2016CFB625), Key Research and Development Project of Hainan Province of China (grant no. ZDYF2018115) and Medical Innovation Project in Fujian Province (grant no. 2017-CX-48).

\section{Availability of data and materials}

All data generated or analyzed during this study are included in this published article.

\section{Authors' contributions}

HX and DW conceived and designed the study. QW and ZL performed the surgical procedures. YL and ZH participated in the experimental design. ZL and YC performed the experiments. MF and SL analyzed the data. HX and DW wrote the manuscript and all authors contributed to the final manuscript. All authors read and approved the final manuscript.

\section{Ethics approval and consent to participate}

The present study was approved by the Institutional Ethical Committee of Tongji Hospital, Tongji Medical College, Huazhong University of Science and Technology (Hubei, China; no. TJ-A20150804).

\section{Patient consent for publication}

Not applicable.

\section{Competing interests}

The authors declare that they have no competing interests.

\section{References}

1. Shi J, Bei Y, Kong X, Liu X, Lei Z, Xu T, Wang H, Xuan Q, Chen $\mathrm{P}, \mathrm{Xu} \mathrm{J}$, et al: miR-17-3p contributes to exercise-induced cardiac growth and protects against myocardial ischemia-reperfusion injury. Theranostics 7: 664-676, 2017.

2. Liu X, Xiao J, Zhu H, Wei X, Platt C, Damilano F, Xiao C, Bezzerides V, Boström P, Che L, et al: miR-222 is necessary for exercise-induced cardiac growth and protects against pathological cardiac remodeling. Cell Metab 21: 584-595, 2015.

3. Burley DS, Ferdinandy P and Baxter GF: Cyclic GMP and protein kinase- $G$ in myocardial ischaemia-reperfusion: Opportunities and obstacles for survival signaling. $\mathrm{Br} \mathrm{J}$ Pharmacol 152: 855-869, 2007.

4. Wong GT, Yao L, Xia Z and Irwin MG: Intrathecal morphine remotely preconditions the heart via a neural pathway. J Cardiovasc Pharmacol 60: 172-178, 2012.

5. Ding X, Ardell JL, Hua F, McAuley RJ, Sutherly K, Daniel JJ and Williams CA: Modulation of cardiac ischemia-sensitive afferent neuron signaling by preemptive $\mathrm{C} 2$ spinal cord stimulation: Effect on substance P release from rat spinal cord. Am J Physiol Regul Integr Comp Physiol 294: R93-R101, 2008.

6. Sroka K: On the genesis of myocardial ischemia. Z Kardiol 93: 768-783, 2004.

7. Zipes DP: Heart-brain interactions in cardiac arrhythmias: Role of the autonomic nervous system. Cleve Clin J Med 75 (Suppl 2): S94-S96, 2008.

8. Armour JA: Cardiac neuronal hierarchy in health and disease. Am J Physiol Regul Integr Comp Physiol 287: R262-R271, 2004.

9. Armour JA, Linderoth B, Arora RC, DeJongste MJ, Ardell JL, Kingma JG Jr, Hill M and Foreman RD: Long-term modulation of the intrinsic cardiac nervous system by spinal cord neurons in normal and ischaemic hearts. Auton Neurosci 95: 71-79, 2002.

10. Pozzati A, Pancaldi LG, Di Pasquale G, Pinelli G and Bugiardini R: Transient sympathovagal imbalance triggers 'ischemic' sudden death in patients undergoing electrocardiographic Holter monitoring. J Am Coll Cardiol 27: 847-852, 1996.

11. Airaksinen KE: Autonomic mechanisms and sudden death after abrupt coronary occlusion. Ann Med 31: 240-245, 1999.

12. Xu LJ, Liu TT, He ZG, Hong QX and Xiang HB: Hypothesis: CeM-RVLM circuits may be implicated in sudden unexpected death in epilepsy by melanocortinergic-Sympathetic signaling. Epilepsy Behav 45: 124-127, 2015.

13. Li R, Wong GT, Wong TM, Zhang Y, Xia Z and Irwin MG: Intrathecal morphine preconditioning induces cardioprotection via activation of delta, kappa, and mu opioid receptors in rats. Anesth Analg 108: 23-29, 2009.

14. Lu Y, Hu J, Zhang Y, Dong CS and Wong GT: Remote intrathecal morphine preconditioning confers cardioprotection via spinal cord nitric oxide/cyclic guanosine monophosphate/protein kinase G pathway. J Surg Res 193: 43-51, 2015.

15. Jiang L, Hu J, He S, Zhang L and Zhang Y: Spinal neuronal NOS signaling contributes to morphine cardioprotection in ischemia reperfusion injury in rats. J Pharmacol Exp Ther 358: 450-456, 2016.

16. Mei B, Li W, Cheng X, Liu X, Gu E and Zhang Y: Activating mu-opioid receptors in the spinal cord mediates the cardioprotective effect of remote preconditioning of trauma. Cardiol J 24: 314-323, 2017. 
17. Wimalawansa SJ: Calcitonin gene-related peptide and its receptors: Molecular genetics, physiology, pathophysiology, and therapeutic potentials. Endocr Rev 17: 533-585, 1996.

18. Wang Y, Chen AF and Wang DH: ET(A) receptor blockade prevents renal dysfunction in salt-sensitive hypertension induced by sensory denervation. Am J Physiol Heart Circ Physiol 289: H2005-H2011, 2005.

19. Wu S, Marie Lutz B, Miao X, Liang L, Mo K, Chang YJ, Du P, Soteropoulos P, Tian B, Kaufman AG, et al: Dorsal root ganglion transcriptome analysis following peripheral nerve injury in mice. Mol Pain 12: 2016.

20. Wang S, Xu H, Zou L, Xie J, Wu H, Wu B, Yi Z, Lv Q, Zhang X, Ying $\mathrm{M}$, et al: LncRNA uc.48+ is involved in diabetic neuropathic pain mediated by the $\mathrm{P} 2 \mathrm{X}$ receptor in the dorsal root ganglia. Purinergic Signal 12: 138-148, 2015.

21. Boon RA, Jae N, Holdt L and Dimmeler S: Long noncoding RNAs: From clinical genetics to therapeutic targets? J Am Coll Cardiol 67: 1214-1226, 2016.

22. Zhao X, Tang Z, Zhang H, Atianjoh FE, Zhao JY, Liang L, Wang W, Guan X, Kao SC, Tiwari V, et al: A long noncoding RNA contributes to neuropathic pain by silencing Kena2 in primary afferent neurons. Nat Neurosci 16: 1024-1031, 2013.

23. Jiang BC, Sun WX, He LN, Cao DL, Zhang ZJ and Gao YJ: Identification of lncRNA expression profile in the spinal cord of mice following spinal nerve ligation-induced neuropathic pain. Mol Pain 11: 43, 2015.

24. Wang Q, Li ZX, Liu BW, He ZG, Liu C, Chen M, Liu SG, Wu WZ and Xiang HB: Altered expression of differential gene and lncRNA in the lower thoracic spinal cord on different time courses of experimental obstructive jaundice model accompanied with altered peripheral nociception in rats. Oncotarget 8: 106098-106112, 2017.

25. Liu Y, Li G, Lu H, Li W, Li X, Liu H, Li X, Li T and Yu B: Expression profiling and ontology analysis of long noncoding RNAs in post-ischemic heart and their implied roles in ischemia/reperfusion injury. Gene 543: 15-21, 2014.

26. Liu Y, Zhou D, Li G, Ming X, Tu YF, Tian J, Lu H and Yu B: Long non coding RNA-UCA1 contributes to cardiomyocyte apoptosis by suppression of p27 expression. Cell Physiol Biochem 35: 1986-1998, 2015.

27. Vausort M, Wagner DR and Devaux Y: Long noncoding RNAs in patients with acute myocardial infarction. Circ Res 115: 668-677, 2014.

28. Grote P, Wittler L, Hendrix D, Koch F, Währisch S, Beisaw A, Macura K, Bläss G, Kellis M, Werber M and Herrmann BG: The tissue-specific lncRNA Fendrr is an essential regulator of heart and body wall development in the mouse. Dev Cell 24: 206-214, 2013.

29. Klattenhoff CA, Scheuermann JC, Surface LE, Bradley RK, Fields PA, Steinhauser ML, Ding H, Butty VL, Torrey L, Haas $S$, et al: Braveheart, a long noncoding RNA required for cardiovascular lineage commitment. Cell 152: 570-583, 2013

30. National Research Council (US) Committee for the Update of the Guide for the Care and Use of Laboratory Animals: Guide for the Care and Use of Laboratory Animals, 8th edition. National Academies Press (US), Washington, DC, 2011.

31. Murry CE, Jennings RB and Reimer KA: Preconditioning with ischemia: A delay of lethal cell injury in ischemic myocardium. Circulation 74: 1124-1136, 1986.

32. Huang CH, Lai CC, Yang AH and Chiang SC: Myocardial preconditioning reduces kidney injury and apoptosis induced by myocardial ischaemia and reperfusion. Eur J Cardthorac Surg 48: 382-391, 2015.

33. Li ZX, Lin Q, He ZG, Wang Q, Chen YL, Feng MH, Li SY and Xiang HB: Altered myocardial gene expression profiling in the ischemic tissues at different time points after cardiac ischemia/reperfusion in rats. Oncotarget 9, 2018

34. Flecknell PA: Anaesthesia of animals for biomedical research. Br J Anaesth 71: 885-894, 1993.

35. Liu QQ, Liu H, He ZG, Zhang SJ, Liu BW, Wang L, Qiu WH, Xu Q, Xiang HB and Lv YM: Differential gene and lncRNA expression in the lower thoracic spinal cord following ischemia/reperfusion-induced acute kidney injury in rats. Oncotarget 8: 53465-53481, 2017.

36. Liu BW, Li ZX, He ZG, Liu C, Xiong J and Xiang HB: Altered expression of target genes of spinal cord in different itch models compared with capsaicin assessed by RT-qPCR validation. Oncotarget 8: 74423-74433, 2017.

37. He ZG, Liu BW, Li ZX, Liu C and Xiang HB: Altered expression profiling of spinal genes modulated by compound $48 / 80$ in a mouse itch model. J Anesth Perioper Med 4: 220-224, 2017.
38. Orom UA, Derrien T, Beringer M, Gumireddy K, Gardini A, Bussotti G, Lai F, Zytnicki M, Notredame C, Huang Q, et al: Long noncoding RNAs with enhancer-like function in human cells. Cell 143: 46-58, 2010.

39. Bottomly D, Walter NA, Hunter JE, Darakjian P, Kawane S, Buck KJ, Searles RP, Mooney M, McWeeney SK and Hitzemann R: Evaluating gene expression in C57BL/6J and DBA/2J mouse striatum using RNA-Seq and microarrays. PLoS One 6: e17820, 2011

40. Xu Y, Zhang XH and Pang YZ: Association of tyrosinase (TYR) and tyrosinase-related protein 1 (TYRP1) with melanic plumage color in korean quails (Coturnix coturnix). Asian-Australas J Anim Sci 26: 1518-1522, 2013.

41. Schmittgen TD and Livak KJ: Analyzing real-time PCR data by the comparative C(T) method. Nat Protoc 3: 1101-1108, 2008.

42. Peng J, Lu R, Ye F, Deng HW and Li YJ: The heme oxygenase-1 pathway is involved in calcitonin gene-related peptide-mediated delayed cardioprotection induced by monophosphoryl lipid A in rats. Regul Pept 103: 1-7, 2002.

43. Kawai S, Yamada T, Matsuura T, Funao T and Nishikawa K: Neuropathic pain attenuates ischemia reperfusion injury through beta2-adrenergic pathway. Life Sci 187: 9-16, 2017.

44. Redington KL, Disenhouse T, Strantzas SC, Gladstone R, Wei C, Tropak MB, Dai X, Manlhiot C, Li J and Redington AN: Remote cardioprotection by direct peripheral nerve stimulation and topical capsaicin is mediated by circulating humoral factors. Basic Res Cardiol 107: 241, 2012.

45. Chiu JH, Cheng YF, Wang JY and Hsu CF: Remote pharmacological preconditioning on median nerve territory increases Hsp32 expression and attenuates ischemia-reperfusion injury in rat heart. Life Sci 90: 629-636, 2012.

46. Polhemus DJ, Gao J, Scarborough AL, Trivedi R, McDonough KH, Goodchild TT, Smart F, Kapusta DR and Lefer DJ: Radiofrequency renal denervation protects the ischemic heart via inhibition of GRK2 and increased nitric oxide signaling. Circ Res 119: 470-480, 2016.

47. Miura T, Kawamura S, Tatsuno H, Ikeda Y, Mikami S, Iwamoto H, Okamura T, Iwatate M, Kimura M, Dairaku Y, et al: Ischemic preconditioning attenuates cardiac sympathetic nerve injury via ATP-sensitive potassium channels during myocardial ischemia. Circulation 104: 1053-1058, 2001.

48. Foreman RD, Garrett KM and Blair RW: Mechanisms of cardiac pain. Compr Physiol 5: 929-960, 2015.

49. Santos SF, Rebelo S, Derkach VA and Safronov BV: Excitatory interneurons dominate sensory processing in the spinal substantia gelatinosa of rat. J Physiol 581: 241-254, 2007.

50. Franco-Cereceda A, Kallner G and Lundberg JM: Capsazepinesensitive release of calcitonin gene-related peptide from C-fibre afferents in the guinea-pig heart by low $\mathrm{pH}$ and lactic acid. Eur $\mathrm{J}$ Pharmacol 238: 311-316, 1993.

51. Steagall RJ, Sipe AL, Williams CA, Joyner WL and Singh K: Substance $P$ release in response to cardiac ischemia from rat thoracic spinal dorsal horn is mediated by TRPV1. Neuroscience 214: 106-119, 2012.

52. Ye DW, Li RC, Wu W, Liu C, Ni D, Huang QB, Ma X, Li HZ, Yang $\mathrm{H}$, Xiang HB and Zhang X: Role of spinal cord in regulating mouse kidney: A virally mediated trans-synaptic tracing study. Urology 79: 745 e741-744, 2012.

53. Cheng YC, Tsai RY, Sung YT, Chen IJ, Tu TY, Mao YY and Wong CS: Melatonin regulation of transcription in the reversal of morphine tolerance: Microarray analysis of differential gene expression. Int J Mol Med 43: 791-806, 2019.

54. Mohrman AE, Farrag M, Huang H, Ossowski S, Haft S, Shriver LP and Leipzig ND: Spinal cord transcriptomic and metabolomic analysis after excitotoxic injection injury model of syringomyelia. J Neurotrauma 34: 720-733, 2017.

55. Niu YL, Guo Z and Zhou RH: Up-regulation of TNF-alpha in neurons of dorsal root ganglia and spinal cord during coronary artery occlusion in rats. Cytokine 47: 23-29, 2009.

56. Schulz R, Gorge PM, Gorbe A, Ferdinandy P, Lampe PD and Leybaert L: Connexin 43 is an emerging therapeutic target in ischemia/reperfusion injury, cardioprotection and neuroprotection. Pharmacol Ther 153: 90-106, 2015.

57. Ding X, Hua F, Sutherly K, Ardell JL and Williams CA: C2 spinal cord stimulation induces dynorphin release from rat $\mathrm{T} 4$ spinal cord: Potential modulation of myocardial ischemia-sensitive neurons. Am J Physiol Regul Integr Comp Physiol 295: R1519-R1528, 2008. 
58. Hua F, Ardell JL and Williams CA: Left vagal stimulation induces dynorphin release and suppresses substance $P$ release from the rat thoracic spinal cord during cardiac ischemia. Am J Physiol Regul Integr Comp Physiol 287: R1468-R1477, 2004.

59. Howard-Quijano K, Takamiya T, Dale EA, Kipke J, Kubo Y, Grogan T, Afyouni A, Shivkumar K and Mahajan A: Spinal cord stimulation reduces ventricular arrhythmias during acute ischemia by attenuation of regional myocardial excitability. Am J Physiol Heart Circ Physiol 313: H421-H431, 2017.

60. Liao SY, Liu Y, Zuo M, Zhang Y, Yue W, Au KW, Lai WH, Wu Y, Shuto $\mathrm{C}$, Chen $\mathrm{P}$, et al: Remodelling of cardiac sympathetic re-innervation with thoracic spinal cord stimulation improves left ventricular function in a porcine model of heart failure. Europace 17: 1875-1883, 2015.

61. Haider T, Hoftberger R, Ruger B, Mildner M, Blumer R, Mitterbauer A, Buchacher T, Sherif C, Altmann P, Redl H, et al: The secretome of apoptotic human peripheral blood mononuclear cells attenuates secondary damage following spinal cord injury in rats. Exp Neurol 267: 230-242, 2015.

62. Ashique AM, Choe Y, Karlen M, May SR, Phamluong K, Solloway MJ, Ericson J and Peterson AS: The Rfx4 transcription factor modulates Shh signaling by regional control of ciliogenesis. Sci Signal 2: ra70, 2009.

63. Zhao B, Pan Y, Xu H and Song X: Hyperbaric oxygen attenuates neuropathic pain and reverses inflammatory signaling likely via the Kindlin-1/Wnt-10a signaling pathway in the chronic pain injury model in rats. J Headache Pain 18: 1, 2017.

64. Harrison BJ, Venkat G, Hutson T, Rau KK, Bunge MB, Mendell LM, Gage FH, Johnson RD, Hill C, Rouchka EC, et al: Transcriptional changes in sensory ganglia associated with primary afferent axon collateral sprouting in spared dermatome model. Genom Data 6: 249-252, 2015.

65. Ke C, Gao F, Tian X, Li C, Shi D, He W and Tian Y: Slit2/Robol mediation of synaptic plasticity contributes to bone cancer pain Mol Neurobiol 54: 295-307, 2017.
66. Knowlton WM, Palkar R, Lippoldt EK, McCoy DD, Baluch F, Chen J and McKemy DD: A sensory-labeled line for cold: TRPM8-expressing sensory neurons define the cellular basis for cold, cold pain, and cooling-mediated analgesia. J Neurosci 33: 2837-2848, 2013.

67. Wang Q, He ZG, Li ZX, Li SY, Chen YL, Feng MH, Hong QX and Xiang HB: Bioinformatics analysis of gene expression profile data to screen key genes involved in cardiac ischemia-reperfusion injury. Int J Clin Exp Med 11: 4955-4966, 2018.

68. Li TP, Guo Z, Liu CJ, Sun T, Chen L and Zhao X: Association of down-regulation of calcitonin gene-related peptide and substance $\mathrm{P}$ with increase of myocardial vulnerability in diabetic neuropathic rats. Peptides 96: 1-7, 2017.

69. Cheng YF, Chang YT, Chen WH, Shih HC, Chen YH, Shyu BC and Chen CC: Cardioprotection induced in a mouse model of neuropathic pain via anterior nucleus of paraventricular thalamus. Nat Commun 8: 826, 2017.

70. Hausenloy DJ and Yellon DM: Myocardial ischemia-reperfusion injury: A neglected therapeutic target. J Clin Invest 123: 92-100, 2013 .

71. Liu T, He Z, Tian X, Kamal GM, Li Z, Liu Z, Liu H, Xu F, Wang J and Xiang H: Specific patterns of spinal metabolites underlying alpha-Me-5-HT-evoked pruritus compared with histamine and capsaicin assessed by proton nuclear magnetic resonance spectroscopy. Biochim Biophys Acta Mol Basis Dis 1863: 1222-1230, 2017.

This work is licensed under a Creative Commons Attribution-NonCommercial-NoDerivatives 4.0 International (CC BY-NC-ND 4.0) License. 